which works quite independently of carbonic anhydrase. Dr. Roughton, in a concluding survey of the present experimental evidence, suggested that there might be at least one more chemical mechanism for carbon dioxide transport in blood besides those already postulated.

Dr. G. A. Millikan (Cambridge) gave a useful résumé of Svedberg's work upon the molecular weight of the respiratory pigments. The values obtained in different animals range from 17,000 in the Chironomus larva to $5,000,000$ in the edible snail and most gastropods. The physiological significance of the enormous variation was discussed. Dr. Millikan then described in detail the properties of the newly isolated muscle hæmoglobin, with particular emphasis upon the striking respects in which it differs, as regards its reactivity, from blood hæmoglobin. This led him finally to a survey of present theories as to the nature of the equilibrium between oxygen and hæmoglobin.
F. J. W. R.

\title{
Distribution of Marine Animals and the History of the Continents
}

$\mathrm{H}^{\mathrm{o}}$ W the past history of the great land and water masses of the earth's crust is reflected in the distribution of many marine animals was the subject of an important paper read by Prof. J. Versluys on September 7 before Section D (Zoology) of the British Association meeting in Aberdeen.

Prof. Versluys directed attention to the fact that the presence of a considerable number of closely allied marine animals and even specifically identical ones on both sides of Central America and in the Indian Ocean and European Atlantic points conclusively to the presence of former sea connexions linking up the Atlantic, the Pacific and the Indian Oceans. These connexions lay across Central America and through a bygone sea called Thetys, along the region where Asia and Africa now unite. In elaborating this thesis, he dealt mainly with the curious distribution of a small family of deep-water horny corals, the Primnoids.

In spite of the great land barrier now separating them, the Primnoid fauna of the European Atlantic is very similar to that of the Indo-Malayan seas, every species in the one region being represented by corresponding and, in part, closely allied species in the other. This is due to the fact that these two regions were in communication by way of the Thetys until the middle of the Tertiary period - a date so recent that no great changes in the Primnoid fauna have since then taken place.

The West Indian Primnoids, on the other hand, differ more widely from the European ones than do those of the Indo-Malayan region. Prof. Versluys suggested that this is explained by the intervention of the big Atlantic basin which, for Primnoids with their very ineffective means of dispersal, must act as a considerable barrier to distribution. Nevertheless, the difference between the West Indian and European Primnoids, though considerable, is not so great as might. on this account have been expected. The Central Atlantic formerly had a continuous southern coast, Brazil and West Africa being united, so that conditions for dispersal between European seas and the West Indies were more favourable in times past than they are now.

Contrary also to what one would expect, the West Indian fauna of Primnoids bears but little resemblance to that of the American Pacific coast, no closely allied species being known from both regions. This applies not only to the Primnoids of these regions but also to the Gorgonacean corals as well. The old Central American connexion was, for some reason, not favourable to the distribution of corals across it.

Again, the American Pacific fauna of Primnoids shows no close relationship with the Indo-Malayan and Japanese fauna. There are a few species in common-indicating a migration across, or more probably around, the Pacific-but a number of important genera have very different species in the two regions, proving that, on the whole, distribution has been restricted and that these faunas must have been separated by the large Pacific basin for a very long time.

In view of these findings, Prof. Versluys is confident that Central America is, and has been, the most formidable distributional barrier encountered by the circum-tropical fauna of Primnoids. The Pacific Ocean also was, and is, an important barrier, but the present obstacle provided by the Africa-Asia continent was absent in pre-Tertiary times when the Thetys offered favourable conditions for the dispersal of Primnoids--so much so that Indo-Malayan forms seem to have reached the West Indies by way of this ancient sea and the then smaller and circum. scribed Atlantic.

In support of these conclusions, comparison was made with the distribution of sea urchins. In spite of the fact that these animals live in shallower water (where stronger currents usually occur) than do the Primnoids, and have specialised pelagic larval stages of some duration which can be transported over long distances by water movement, the sea urchin faunal regions in the tropics and sub-tropics are the same as those of the Primnoids. The Atlantic again has proved but a feeble barrier. Of about eighty West Indian species, 19 are found also in the European Atlantic. On the other hand, there is no speeies of sea urchin known from both sides of Central America, and the tropical American Pacific coast has no species in common with the Indo-Malayan region.

The Primnoid fauna of the southern oceans also has a curious distribution, the explanation for which must be sought in the geological formations of earlier times. The southern Primnoids, especially those of the genus Primnoella, are found at a number of stations widely separated from one another by stretches of sea that must be scarcely passable for these corals with their very limited means of distribution. Moreover, of the entire southern fauna of Primnoids, only two-species of Parathonarellaare recorded from South Africa. The simplest explanation of this curiously scattered distribution, according to Prof. Versluys, is offered by Wegener's well-known theory of the splitting, up of a southern continental mass known as Gondwanaland, the parts of which drifted away from one another to form South America, Australia, Africa, part of India and the antaretic continent, with some intermediate small islands representing parts that split off from the drifting mainlands and were left behind.

G. A. S. 